\title{
ZERO-DIVISOR GRAPHS OF REDUCED RICKART *-RINGS
}

\author{
A.A. PATIL \\ Department of Mathematics \\ Garware College of Commerce, Pune-411004, India \\ e-mail: avipmj@gmail.com \\ AND \\ B.N. WAPHARE \\ Center for Advanced Studies in Mathematics \\ Department of Mathematics \\ Savitribai Phule Pune University, Pune-41100\%, India \\ e-mail: waphare@yahoo.com \\ bnwaph@math.unipune.ac.in
}

\begin{abstract}
For a ring $A$ with an involution *, the zero-divisor graph of $A, \Gamma^{*}(A)$, is the graph whose vertices are the nonzero left zero-divisors in $A$ such that distinct vertices $x$ and $y$ are adjacent if and only if $x y^{*}=0$. In this paper, we study the zero-divisor graph of a Rickart *-ring having no nonzero nilpotent element. The distance, diameter, and cycles of $\Gamma^{*}(A)$ are characterized in terms of the collection of prime strict ideals of $A$. In fact, we prove that the clique number of $\Gamma^{*}(A)$ coincides with the cellularity of the hullkernel topological space $\Sigma(A)$ of the set of prime strict ideals of $A$, where cellularity of the topological space is the smallest cardinal number $m$ such that every family of pairwise disjoint non-empty open subsets of the space have cardinality at most $m$.
\end{abstract}

Keywords: reduced ring, Rickart *-ring, zero-divisor graph, prime strict ideals.

2010 Mathematics Subject Classification: Primary: 16W10, Secondary: 05C25, 05C15. 


\section{REFERENCES}

[1] S. Akbari and A. Mohammadian, On the zero-divisor graph of a commutative ring, J. Algebra 274 (2004) 847-855. doi:10.1016/S0021-8693(03)00435-6

[2] D.F. Anderson, R. Levy and J. Shapirob, Zero-divisor graphs, von Neumann regular rings and Boolean algebras, J. Pure Appl. Alg. 180 (2003) 221-241. doi:10.1016/S0022-4049(02)00250-5

[3] D.F. Anderson and P.S. Livingston, The zero-divisor graph of a commutative ring, J. Algebra 217 (1999) 434-447. doi:10.1006/jabr.1998.7840

[4] I. Beck, Coloring of commutative rings, J. Algebra 116 (1988) 208-226. doi:10.1016/0021-8693(88)90202-5

[5] S.K. Berberian, Baer *-Rings (Springer-Verlag, Berlin and New York, 1972).

[6] D. Dolžan and P. Oblak, The zero divisor graphs of rings and semirings, Int. J. Algebra Comput. 221250033 (2012) 20pp. doi:10.1142/S0218196712500336

[7] F. DeMeyer, T. McKenzie and K. Schneider, The zero-divisor graph of a commutative semigroup, Semigroup Forum 65 (2002) 206-214. doi:10.1007/s002330010128

[8] F. DeMeyer and L. DeMeyer, Zero divisor graph of Semigroups, J. Algebra 283 (2005) 190-198. doi:10.1016/j.jalgebra.2004.08.028

[9] R. Halaš and M. Jukl, On Beck's colouring of posets, Discrete Math. 309 (2009) 4584-4589. doi:10.1016/j.disc.2009.02.024

[10] R. Sen Gupta, M.K. Sen and S. Ghosh, A variation of zero-divisor graphs, Discuss. Math. Gen. Algebra Appl. 35 (2015) 159-176.

doi:10.7151/dmgaa.1238

[11] K. Samei, The zero divisor graph of a reduced ring, J. Pure App. Alg. 209 (2007) 813-821. doi:10.1016/j.jpaa.2006.08.008.

[12] S.K. Nimbhorkar, Coloring of Rickart *-rings, Trends in Theory of Rings and Modules, S. Tariq Rizvi and S.M.A. Zaidi (Eds.) Anamya Publishers (New Delhi 2005), 91-95.

[13] S.K. Nimbhorkar, M.P. Wasadikar and L. DeMeyer, Coloring of semilattices, Ars Comb. 12 (2007) 97-104.

[14] Avinash Patil and B.N. Waphare, On the Zero-divisor graph of Rickart *-rings, Asian-Eur. J. Math. 10 (2017) 1750015 (17 pages). doi:10.1142/S1793557117500152 
[15] Avinash Patil, B.N. Waphare, V.V. Joshi and H.Y. Paurali, Zero-divisor graphs of lower dismantlable lattices-I, Math. Slovaca 67 (2017) 1-12.

[16] Avinash Patil, B.N. Waphare and V.V. Joshi, Zero-divisor graphs of lower dismantlable lattices-II, to appear in Math. Slovaca.

[17] Avinash Patil and B.N. Waphare, The zero-divisor graph of a ring with involution, J. Algebra Appl. (to appear).

[18] S.P. Redmond, The zero-divisor graph of a non-commutative ring, Int. J. Commut. Rings 1 (2002) 203-211.

[19] N.K. Thakare and S.K. Nimbhorkar, Prime strict ideals in Rickart ${ }^{*}$-rings, Ind. J. Pure appl. Math. 22 (1991) 63-72.

[20] D.B. West, Introduction to Graph Theory, Second Edition (Prentice-Hall of India, New Delhi, 2002).

Received 28 June 2016

1st Revised 17 October 2016

2st Revised 23 January 2017 
